TRANS · núm. 25.2021

ARTÍCULOS BIBLIOGRÁFICOS · 565-581

Este trabajo ofrece una recopilación de traducciones al español de los Sonetos de William Shakespeare publicadas entre 1877, fecha en que apareció la primera traducción de la obra, y 2019. Pese a que la obra original, publicada en 1609, no gozó de gran fama en sus inicios (Blakmore Evans, 2006: 2), a partir de principios del siglo XIX, los Sonetos fueron una fuente de especulación sobre asuntos biográficos (Burrow, 2002: 2), lo que pudo desembocar en un mayor impacto de la obra en los últimos siglos, no solo en el ámbito anglosajón, sino también en el hispanohablante, como lo demuestra este trabajo. En él se indican, además de los traductores de esta obra al español y las fechas y países de publicación, algunas características relevantes de cada una de las traducciones, como la forma empleada para traducir los sonetos, la presencia de prólogos y otros paratextos o el carácter bilingüe/monolingüe de las ediciones.

PALABRAS CLAVE: Sonetos, Shakespeare, bibliografía, España, Latinoamérica.

\title{
Panorámica de las traducciones de los Sonetos de Shakespeare al español
}

\author{
TANYA EsCUdERO \\ Universidad de Tallin
}

\section{An Overview of the Translations of Shakespeare's Sonnets into Spanish}

This work provides a compilation of Spanish translations of William Shakespeare's Sonnets published between 1877, when the first translation of the work appeared, and 2019. Although the original book, published in 1609, did not enjoy great popularity in its early days (Blakmore Evans, 2006: 2), from the beginning of the $19^{\text {th }}$ century, the Sonnets were a source of speculation regarding biographical questions (Burrow, 2002: 2), which may have led to a greater impact of the work in recent centuries, not only in the English-speaking world, but also in the Spanish-speaking world, as shown by this paper. In addition to the translators of this work into Spanish and the dates and countries of publication, this article indicates some relevant characteristics of each of the translations, such as the form used to translate the sonnets, the presence of prologues and other paratexts, or the bilingual/monolingual nature of the editions.

KEY WORDS: Sonnets, Shakespeare, bibliography, Spain, Latin America. 


\section{1. INTRODUCCIÓN}

Este estudio es una revisión bibliográfica de las traducciones al español de los Sonetos de Shakespeare publicadas principalmente en España y Latinoamérica, desde 1877 hasta 2019 y ha servido como base a un trabajo más amplio sobre la traducción de la forma poética (Escudero, 2021). En esta compilación he incluido todas las traducciones parciales que han aparecido en antologías, revistas, periódicos y publicaciones culturales en papel de las que tengo conocimiento, en lugar de limitar la lista a las ediciones en formato de libro, a fin de poder incluir traducciones parciales más tempranas publicadas en revistas. Sin embargo, no he incorporado traducciones más recientes autoeditadas ni otras que solo se han publicado en formato digital, como blogs, revistas digitales, etc. La razón obedece a que la cantidad de material publicado en este tipo de formato es actualmente abrumadora y en muchos casos no ha pasado ningún proceso de filtrado externo.

A pesar de que los Sonetos de Shakespeare aparecieron por primera vez en Inglaterra en 1609, no fue hasta 1877 cuando apareció la primera traducción parcial, y la primera traducción de la obra completa no llegó hasta 1929. A partir de la década de 1970, comenzó a aparecer un mayor número de traducciones de este libro. De hecho, en esta década se publicaron tres traducciones completas en España, el mismo número que se había publicado en las ocho décadas anteriores. Esto parece estar en línea con lo que Campillo Arnaiz (2005: 77) afirma sobre las traducciones de las obras dramáticas de Shakespeare, que experimentaron un auge en esta misma década. Es posible, por lo tanto, que el deseo de traducir a Shakespeare y el interés de los editores por sus Sonetos fueran impulsados por el impacto de sus obras dramáticas. Aún más llamativo es el gran número de traducciones completas publicadas en las dos últimas décadas; entre 2000 y 2019 se publicaron 18 traducciones de los 154 sonetos. Varios factores pueden haber contribuido a ello, como el mayor reconocimiento de Shakespeare en el mundo de habla hispana, un mayor volumen de publicaciones debido al aumento del número de editores, el creciente interés por traducir obras extranjeras y la conmemoración de fechas clave relacionadas con esta obra, como el $400^{\circ}$ aniversario de la publicación de los sonetos en Inglaterra (en 2009 se publicaron las traducciones de Law Palacín, Ehrenhaus y Gamen, así como varias reimpresiones de otras traducciones y la compilación de las traducciones más tempranas, editada por Pujante). Lo que no parece haber aumentado significativamente en este casi siglo y medio es el número de traducciones realizadas por mujeres, solo 7 de las 99 traducciones aquí enumeradas han sido realizadas exclusivamente por mujeres (la mayoría de ellas antes de la década de 1970) y 4 han sido realizadas por mujeres y hombres de manera colaborativa.

Aunque ha surgido un mayor número de traducciones del libro completo en las últimas décadas, la mayoría de las que se enumeran a continuación son traducciones parciales, por lo que indicaré qué sonetos incluye cada una de ellas. Por otra parte, dada la relevancia de los estudios paratextuales en las últimas décadas en el campo de la traducción, indico qué ediciones constan de prólogos o notas introductorias. Señalo además si se trata de ediciones bilingües, así como la forma general utilizada para traducir el soneto shakespeariano o isabelino. Pese a que este está, en sentido estricto, compuesto por pentámetros yámbicos, al referirme a las traducciones, denomino aquí soneto isabelino a los poemas en español compuestos en endecasílabos que riman siguiendo el mismo esquema del soneto isabelino inglés, es decir, ABAB CDCD 
EFEF GG. Además, empleo el término 'soneto castellano' para designar aquellos poemas en endecasílabos agrupados en dos cuartetos (ABBA ABBA) pero combinados con dos tercetos de diversa índole (CDC DCD, CDE CDE, CDD CDD, CDE DCE, etc.), algo frecuente en la lírica en español (López Hernández 1998, 9-12), aunque la forma canónica del soneto petrarquista emplee tercetos encadenados.

La fecha y el país de publicación (y no el país de origen del traductor) que indico entre paréntesis se refieren a la primera traducción publicada que he podido localizar de dicho traductor, pero también he anotado dentro de cada entrada los casos en que hay varias versiones realizadas por el mismo traductor. Si bien la mayoría de las traducciones aquí recogidas han sido publicadas en España, algunas de estas, especialmente las más antiguas, fueron realizadas por traductores latinoamericanos, como señala Pujante (2009a).

Por último, debo mencionar que para la realización de estas traducciones me he basado en estudios previos, principalmente en el minucioso trabajo realizado por Barcia (1966), Muñoz Calvo (1987), Pujante (2009b), Campillo Arnaiz (2005), Díaz Fernández (2005) y Bistué (2013), sin los cuales esta tarea no habría sido posible. Esta panorámica, además de tratarse de una lista actualizada, hace referencia a algunas traducciones más antiguas que no están incluidas en las fuentes bibliográficas en las que me he basado (como la de Eduardo L. del Palacio, Ángel Johan o María Alfaro). También se incluyen versiones anteriores de algunas traducciones a las indicadas en estas fuentes y correcciones relativas a las fechas de publicación y número de sonetos. En ocasiones, he insertado notas a pie de página para explicar estas correcciones o adiciones. Quedo enormemente agradecida a los investigadores que he nombrado por sus concienzudos y excelentes trabajos. Muchas otras traducciones y versiones anteriores a las que aquí aparecen habrán quedado en el olvido, y estoy segura de que el aumento de bibliotecas y hemerotecas digitales permitirá que esta lista se amplíe y que otros corrijan mis errores y faltas.

\section{PANORÁMICA}

Matías de Velasco y Rojas (1877, España) traduce en prosa comentada treinta y siete sonetos: 2 , $3,7,19,20,25,27,28,29,43,48,50,51,52,53,54$, $55,56,59,60,61,62,63,64,65,66,73,78,113$, $116,123,130,131,137,138,140,146$. Se trata de una edición monolingüe. En 1889, en su libro Sonetos, recoge una traducción más, esta vez realizada en forma de soneto castellano, la del soneto $149^{1}$.

Juan Antonio Pérez Bonalde (1880, Estados Unidos) traduce en verso libre los sonetos 66, 116 y 146, publicados en su colección de poemas Ritmos. Más tarde aparecen recogidos en varias antologías ${ }^{2}$.

Miguel Antonio Caro (1891, Curazao) traduce en forma de soneto isabelino cuatro sonetos, recogidos en la antología Sonetos de aquí y allí. Traducciones y refundiciones: 29 («Retractación»), 43 («Día y noche»), 48 («Amor verdadero») y 116 («Joyas del corazón»). En los dos años posteriores aparecen de nuevo en diversos números de la revista La España Moderna.

Jaime Martí-Miquel (1895, España) traduce en forma de soneto isabelino el soneto 66 , incluido en la antología El ramo de pensamientos. Poesías

I En el Ensayo sobre la literatura inglesa, de Chateaubriand, traducido por Francisco Madina-Veytia y publicado en España en 1871, ya se recogen traducciones en prosa de los sonetos $36,71,73,102$ y 111 , pero son todas fragmentarias (1871: 54).

2 En concreto, Pujante (2009) hace referencia a la Antología de líricos ingleses y angloamericanos (1922) y Poesías y Traducciones (recopilación) (1947), pero no a esta edición de 1880. 
568 de ilustres poetas extranjeros puestas en rima castellana y los sonetos $24,75,87$ y 153 , recogidos en Flores de Luz (1897) ${ }^{3}$.

Guillermo Macpherson (1895, España) traduce en forma de soneto castellano el soneto 111, recogido en la antología Versiones inglesas o arte de traducir el inglés. En 1922, vuelve a publicarse en la Antología de líricos ingleses y angloamericanos, editada por Sánchez Pesquera ${ }^{4}$.

Gregorio Martínez Sierra (1912, España) traduce en prosa el soneto 2 , que recita uno de los personajes en su paso de comedia El Enamorado.

José de Armas y Cárdenas (1915, España) traduce en forma de soneto isabelino el soneto 37, publicado en la revista Blanco y Negro en junio de 1915. En septiembre de ese mismo año se publican 10 sonetos (incluido el 37) en la revista Cuba contemporánea junto a una nota del traductor: $18,25,29,37,66,71,100,121,138,153^{5}$.

Julio Arceval (1916, España), seudónimo de Salvador de Madariaga, traduce en sonetos isabelinos los sonetos 31, 90 y 104, publicados en el semanario España. No se incluye ningún comen-

3 La edición no está fechada. Pujante (2009b) indica como fecha aproximada 1896. Sin embargo, en varias publicaciones de la época, tales como el Boletín bibliográfico español (Almonacid y Cuenca, 1898: 12), señalan 1897 como el año de publicación de la obra.

4 Pujante (2009b: 16) se refiere a la edición póstuma de 1922, al no haber encontrado una edición previa. Eduardo Benot incluye este soneto en su manual Versiones inglesas o el arte de traducir el inglés, de 1895, junto a otras traducciones de Macpherson. Sin embargo, la primera estrofa ya aparecía, como nota al pie, en un estudio preliminar de Benot a la traducción de Macpherson en 1885, por lo que es probable que la traducción del soneto completo se hubiese publicado previamente, pero no he dado con ninguna versión anterior.

5 En nota al pie se indica que los sonetos 25 y 71 (con alguna variación) ya habían sido publicados en la revista $E l$ Fígaro (La Habana) el 20 de junio de 1915 (73). Esta es la primera traducción publicada de Armas y Cárdenas de la que tengo constancia, pero no he podido acceder a ella. tario o nota del traductor. Posteriormente, en 1919, aparecen recogidos en la antología Manojo de poesías inglesas.

José Pablo Rivas (1916, España) traduce en forma de soneto isabelino 10 sonetos, incluidos en la revista Estvdio acompañados de una breve nota: 1, 2, 23, 25, 29, 71, 72, 103, 121, 149. Estos sonetos aparecen luego recogidos la revista argentina Caras y caretas y en varias antologías publicadas en España, como la Antología de poetas extranjeros antiguos y contemporáneos (1920) o Las mejores poesías (líricas) de los mejores poetas (ca. 1920).

Rafael Pombo (1917, Colombia) traduce en forma de soneto castellano 7 sonetos, recogidos en la antología Traducciones poéticas: 2, 11, 13, 27, 73, 95,147 . Se trata de una edición monolingüe que incluye a modo de prólogo un discurso de Lorenzo Marroquín en honor al traductor.

Fernando Maristany (1918, España) traduce 11 sonetos en forma de soneto isabelino: 17,18 , 30, 33, 60, 66, 71, 73, 74, 106, 116. Estos sonetos están incluidos en la antología Las mejores poesías (líricas) de la lengua inglesa, una edición monolingüe precedida por un prólogo de Enrique Díez-Canedo y una breve introducción de Maristany. En 1920, junto a los 10 sonetos anteriores, aparece la traducción de dos sonetos más, el 27 y el 50, en la antología de poesía extranjera Florilegio y en Las mejores poesías (líricas) de los mejores poetas (ca. 1920).

Carmela Eulate Sanjurjo (ca. $1920^{6}$, España)

6 Muñoz Calvo afirma que la antología en la que aparece esta traducción apareció en 1920, Shakespeare. Las mejores poesías (líricas) de los mejores poetas. Pujante (2009), por su parte, indica que en esta antología no aparece fecha de publicación y que bien podría haber aparecido en 1922. Sin embargo, en el número 91 del suplemento Literatura Hispano-Americana, publicado en febrero de 2021, ya se hace referencia a esta traducción de Eulate Sanjurjo (p. 8), por lo que esta edición es claramente anterior a 1922 y aparecería, muy probablemente, en 1920. 
traduce en forma de soneto castellano (con dístico al final) cinco sonetos incluidos en la antología Las mejores poesías (líricas) de los mejores poetas: $32,127,142,143,152$.

Gabriel de Zéndegui (1920, España) traduce en forma de soneto isabelino el soneto 146, incluido en las antologías Sones de la lira inglesa (1920) y Las mejores poesías (líricas) de los mejores poetas (ca. 1920).

Guillermo Belmonte (1922, España) traduce en forma de soneto isabelino 6 sonetos, incluidos en la Antología de líricos ingleses y angloamericanos: 7, 27, 31, 50, 90, 104.

Luis María Díaz (1922, Argentina) traduce tres sonetos en forma de soneto castellano, publicados en la revista Nosotros: 2, 62, 146.

Anselmo Gómez (19277, España) traduce en endecasílabos blancos un soneto, el 116, incluido en la antología Grandes poemas universales, una edición bilingüe con prólogo del traductor.

Mariano de Vedia y Mitre (1927, Argentina) traduce alejandrinos siguiendo el esquema isabelino 43 sonetos en varias revistas. En 1927 aparecen publicados los sonetos 1-16 en el número 69 de Verbum, en 1929 los sonetos 17-26 en el número 73 de la misma revista y en 1937 se publican, en la revista Nosotros, los sonetos 27-43. En 1946

\footnotetext{
7 Muñoz Calvo alude a esta traducción en su artículo, citando una fuente previa, y la fecha de publicación que se indica es 1928. Este año es el mismo que señala Campillo (p. 78 y 468), aunque la edición no está fechada. Sin embargo, he encontrado un par de referencias a este libro en periódicos de la época que me llevan a señalar 1927 como año de publicación: el diario El Imparcial del 23 de octubre de 1927 incluye una crítica de la traducción de Gómez firmada por Astrana Marín (5), mientras que en la sección «Noticias de libros y revistas» del $A B C$ del 4 de noviembre de 1927 se habla de Grandes poemas universales, de Anselmo Gómez, como «este nuevo libro que acaba de darse a la estampa» (20).
}

aparecen traducidos en forma de soneto isabelino el 44 y 45 en el número 29 de la revista Amicitia. El soneto 105 aparece publicado en la antología Joyas de la poesía inglesa. Desde Shakespeare hasta Kipling (1942). En 1954 aparece una edición que recoge todos los sonetos en Buenos Aires, publicada por la Editorial Kraft. Esta incluye un prólogo de más de 100 páginas del propio Vedia y Mitre y los poemas traducidos en forma de soneto isabelino junto al original.

Luis Astrana Marín (1929 ${ }^{\circ}$ España) traduce en prosa todos los sonetos. Esta traducción cuenta con numerosas reediciones por distintas editoriales a lo largo de los años, tanto en volúmenes que recogen las obras completas, como en ediciones que incluyen únicamente los sonetos. Suelen ir acompañadas del prólogo original, escrito por el propio Astrana.

Eduardo L. del Palacio (1936, España) traduce dos sonetos, a los que denomina paráfrasis, en forma de soneto castellano, publicados en la revista Blanco y Negro: 128 («La antorcha de Eros») y 154 («La novia música»).

Patricio Gannon (1940, Argentina) traduce en endecasílabos rimados (dos serventesios y dos tercetos) diez sonetos precedidos de un largo prólogo del traductor en una edición bilingüe: $18,30,32,52,54,64,71,72,96,116$.

8 Esta edición aparece sin fechar. Sin embargo, todas las fuentes apuntan a 1929 como el año de publicación más probable. Entre otros, el diario $\mathrm{La} \mathrm{Voz}$, en su sección «Revista de Libros» (1929: 6), anunciaba ese mismo año la publicación del volumen. Aunque no hay noticias de la publicación de las Obras Completas hasta diciembre de 1929, a principios de ese mismo año, Astrana publica a lo largo de 4 semanas una columna en $E l$ Imparcial en la que incluye ya algunas de sus traducciones. En concreto, la de los sonetos 1, 2, 8, 12, 18, 42 y 128 (17/02); el 20, $40,61,97,98$ y 99 (24/02); y el 77, 79, 80, 81, 85, 86 y parte del 104 (03/03). Las dos primeras estrofas del 18, ya habían aparecido en el diario La Libertad del 10 de enero de 1928. 
570 Eduardo Dieste (1944, Uruguay) traduce en verso libre 21 sonetos: $2,3,6,12,13,14,15,16,17,18$, $21,22,23,24,35,44,60,66,71,74,116$. La edición es bilingüe e incluye un prólogo de Esther de Cáceres.

Angelina Damians de Bulart (1944, España) traduce en forma de soneto castellano los 154 sonetos. La edición es bilingüe e incluye una «breve nota preliminar» de la traductora.

Diego Poyatos (1944, España) traduce en verso 50 sonetos $^{9}$.

Ángel Johán (1945, España), seudónimo de Ángel Juan González López, traduce en forma de soneto isabelino los 7 primeros sonetos.

Marià Manent (1947, España) traduce en alejandrinos blancos 7 sonetos: 18, 73, 97, 98, 102, 106, 146. Aparecen recogidos en la antología (bilingüe) La poesía inglesa. De los primitivos a los neoclásicos (1947) y más tarde (1983) en Poesía inglesa de los siglos XVI $y$ XVII.

Concepción Vázquez Castro (1948, España) traduce en prosa 6 sonetos incluidos en dos ensayos sobre Shakespeare de Derek Traversi: el 138, que aparece como nota al pie en Visión de Shakespeare (1948), y los sonetos 29, 60, 104, 116 y 129, incluidos en el libro Shakespeare (1951).

9 No me ha sido posible encontrar un ejemplar de esta traducción, pero parece ser la misma a la que se refiere Muñoz Calvo cuando alude a una traducción del anónimo «Diepober» de este año. Muñoz Calvo no especifica número de sonetos ni título de la publicación y únicamente aporta la información encontrada en una fuente previa (1986: 93). Los datos que indico aquí están extraídos del "Expediente de censura de Cincuenta sonetos de William Shakespeare en rimas castellanas" número (03)050.000, caja 21/07321. Como dato anecdótico, Diego Poyatos Bermejo (DiePoBer), el traductor de esta obra que fue autorizada por la Delegación Nacional de Propaganda, participó en el fallido golpe de Estado del 10 de agosto de 1932 contra la Segunda República (La Voz, 1932: 1).
Juan Rodolfo Wilcock (1949, Argentina) traduce en prosa 20 sonetos incluidos en la antología Poetas líricos ingleses, editado 50 años más tarde en España por la editorial Océano: 19, 29, 55, 60, $62,64,71,73,76,94,95,97,110,113,116,119,128$, $129,141,146$.

Manuel Mujica Lainez (1952, Argentina) traduce varios sonetos, todos ellos en endecasílabos blancos, publicados en diversas revistas literarias y diarios: cuatro sonetos $(27,30,53$ y 65$)$ en la revista Sur (1952), cinco $(15,39,50,71$ y 91) en La Biblioteca (1957) y cuatro (25, 33, 59 y 96) en el Boletín de la Academia Argentina de Letras $(1958)^{10}$. En 1963, ve la luz Cincuenta sonetos de Shakespeare, precedida por un prólogo de $\mathrm{Mu}$ jica, que, pese al título, incluye únicamente 48 sonetos $^{11}: 1,2,3,4,5,6,7,15,16,17,18,19,20,21$, $22,23,24,25,26,27,29,30,31,32,33,34,35,36$, $37,38,39,40,41,42,43,53,55,59,60,61,62,65$, 71, 91, 96, 106, 123, 146. Posteriormente Visor y Losada publican varias ediciones de esta traducción, entre ellas la que contiene la traducción de Pablo Ingberg de los 106 sonetos restantes.

Vicente Gaos (1958, España) traduce, en forma de soneto castellano, el soneto 2, publicado en la revista Cuadernos de Ágora, bajo el título «Más adorable». Posteriormente, aparece recogido en sus Traducciones poéticas completas (1986), con prólogo de Jaime Siles.

\section{Maggie Howard de Martínez y Alfredo Martí-} nez Howard (1961, Argentina) traducen en forma de soneto castellano (distintas rimas para los serventesios) once sonetos: $1,2,3,16,18,20$,

Io Mujica afirma en el prólogo a Cincuenta sonetos que algunas de estas traducciones han aparecido también en las páginas de La Nación, pero no las he localizado.

II Para crear aún más confusión, Mujica afirma en el prólogo que sus «Cincuenta sonetos son en realidad cuarenta y nueve» (1963: 9). 
30, 54, 55, 97, 132. Edición bilingüe con prólogo de Martínez Howard.

Mario Reyes Suárez (1964, Colombia) traduce en forma de soneto castellano 53 sonetos publicados en la revista Cauce ${ }^{12}: 1,2,3,5,6,8,9,12$, $13,15,16,18,20,21,23,25,29,30,31,39,40,44$, $46,49,50,57,60,64,66,71,73,74,77,81,83,89$, $90,94,97,98,104,105,107,108,116,126,127,128$, 129, 130, 145, 146 y 149. En 1998 aparecen recogidos 35 sonetos más, que se suman a los anteriores, en una edición bilingüe con prólogo de los editores: 4, 7, 14, 17, 19, 24, 26, 27, 36, 41, 42, 52, $55,62,63,75,78,80,84,91,95,96,99,100,101$, 109, 110, 111, 112, 119, 131, 142, 144, 148, y 152.

Olga de la Piedra de Bingham Powell (1964, Perú) traduce en verso libre doce sonetos incluidos en el número 42 de la revista Letras (Lima): 2, 12, 18, 30, 83, 98, 99, 102, 106, 116, 129, 147. En 1993 la editorial Pacific Press recoge de nuevo esta traducción.

Carlos Peregrín Otero (1966, Inglaterra) traduce en forma de soneto castellano con dístico al final el soneto 27, incluido en su ensayo Letras I.

Jorge Guillén (1967, Italia) traduce en endecasílabos blancos tres sonetos incluidos en la sección «Variaciones» de su libro Homenaje: 27, 44 y 97.

José Basileo Acuña (1968, Costa Rica) traduce todos los sonetos en forma de soneto isabelino en una edición bilingüe con prólogo de Alexander Hamilton Ross. En 1999, aparece en Lima una reedición ampliada en la colección El Manantial Oculto, publicada por la Editorial Pontificia de la Universidad Católica del Perú, con prólogo de Óscar Montanaro Meza.

${ }^{12}$ No he conseguido acceder a esta versión. Pujante en 1989 dice los sonetos que incluye (1989: 140).
Ángel J. Battistessa (1969, Argentina) traduce en forma de soneto isabelino en versos alejandrinos cuatro sonetos, incluidos como «nota aneja» de su ensayo sobre Shakespeare Oír con los ojos: 18, 23,99 y $116^{13}$. Del soneto 116 incluye además una versión en endecasílabos. En posteriores ediciones, añade dos sonetos más, el 30 y el 31.

María Alfaro (1972, España) traduce en verso libre los sonetos 71 y 97, publicados en el $A B C$ de Madrid.

Agustín García Calvo (1974, España) traduce todos los sonetos en tridecasílabos rimados siguiendo el esquema isabelino. Estos se incluyen en una edición bilingüe con prólogo de García Calvo.

Jenaro Talens (1974, España) traduce en alejandrinos blancos dos sonetos $(2,76)$, publicados en la revista La Ilustración Poética Española e Iberoamericana. En 1980 añade 10 a la lista (1, $3,18,22,23,81,98,113,114$ y 151) que aparecen publicados en En torno a Shakespeare. Homenaje $a$ T. J. B. Spencer editado por Manuel Cornejero, y en 2014 sale publicada una edición bilingüe con prólogo de Talens que incluye los 154 sonetos.

Fátima Avad y Pablo Mañé (1975, España) traducen en verso libre todos los sonetos y los incorporan a una edición bilingüe que incluye la poesía completa de Shakespeare. Posteriormente, aparecen algunas reediciones que incluyen únicamente los sonetos, con prólogo del editor, Atilio Pentimalli.

José Méndez Herrera (1976, España) traduce en forma de soneto castellano los 154 sonetos. Edición bilingüe con prólogo del traductor.

13 Barcia afirma que el soneto 116 ya había aparecido en el diario La Nación el 19 de abril de 1964, en un artículo titulado «Vigencia y ejemplaridad de Shakespeare». 
572 Mario Jofré (1976, Argentina) traduce todos los sonetos en forma de soneto isabelino. Esta edición es monolingüe e incluye un breve prólogo del traductor ${ }^{14}$. En 1997, se publica una edición bilingüe con los sonetos traducidos en endecasílabos rimados siguiendo diversos patrones (pareados, soneto isabelino, soneto petrarquista...).

Juan Francisco Elvira-Hernández (1977, España) traduce 30 sonetos en versos de diversa longitud rimados siguiendo el esquema isabelino: 1, 2, $3,18,22,30,40,42,43,46,53,54,57,60,61,63,65$, $66,79,82,87,90,100,104,105,106,109,121,123$, 144. Esta edición es bilingüe e incluye un prólogo de Ivy L. Mc. Clelland en inglés y español.

José Siles Artés (1979, España) traduce en verso libre tres sonetos (73, 94 y 116), recogidos en Poesía inglesa. Antología bilingüe. En 2006 se publica la Antología bilingüe de la poesía angloamericana, en la que, además de los tres sonetos anteriores, se incluyen cuatro más: 30, 33, 55 y 71.

Enrique Sordo (1982, España) traduce en verso libre todos los sonetos. Edición bilingüe con prólogo del traductor.

Pedro Vives Heredia (1985, Argentina) traduce en forma de soneto isabelino los once primeros sonetos $^{15}$. Ese año aparece en la misma editorial otra edición que incluye 32 sonetos (aunque algunos de los números se repitan, las traducciones difieren enormemente): 1, 2, 3, 4, 5, 6, 13, 14, 15, dos versiones del 18, 19, 20, 22, 25, 27, 30, 32, 60, 62, 71,

\footnotetext{
${ }^{14}$ No he conseguido esta versión, sino la de 1997. Los datos respecto a la primera edición están extraídos de Montezanti (2005).

${ }^{15}$ El libro explica que se trata de un «Intento de aproximación a unos sonetos que pudo haber escrito William Shakespeare a su hija Susana». El libro se titula «Los sonetos de Shakespeare a su hija Susana». En el prólogo, el traductor cuenta una historia personal que explica el porqué de este título y de la adaptación estos versos como si fuesen a Susana, nombre también de la hija de Vives Heredia.
}

$72,81,91,95,101,104,108,109,123,142,150$ y $154^{16}$. Posteriormente publica la traducción de todos los sonetos en la editorial de autoedición Dunken.

Francisco Núñez Roldán (1986, España) traduce en alejandrinos rimados siguiendo principalmente el esquema isabelino 3 sonetos: $18,77 \mathrm{y}$ 130. Estos están recogidos en la antología bilingüe El Siglo De Oro De La Lírica Inglesa, con prólogo del traductor.

Carmen Pérez Romero (1987, España) traduce todos los sonetos en alejandrinos con rima asonante siguiendo el patrón isabelino. En 2006 publica una edición comentada, con numerosas notas al pie. Hay alteraciones en todos los sonetos, aunque el metro escogido sigue siendo el mismo. Ambas ediciones son bilingües e incluyen prólogo de la traductora.

Mariano Bros (1987, España) traduce 62 sonetos en alejandrinos con rima asonante en los pares y en el dístico final: 2, 12, 18, 23, 26, 27, 29, 30, $33,35,49,50,55,57,60,61,64,65,66,71,72,73$, $74,75,76,80,82,84,85,86,87,89,90,91,83,94$, $95,102,106,110,111,112,113,116,117,118,119,120$, $121,122,129,130,131,138,140,141,143,146,147$, $149,150,152$. Se trata de una versión monolingüe con prólogo del traductor.

Miguel Ángel Montezanti (1987, Argentina) traduce todos los sonetos en alejandrinos o endecasílabos rimados siguiendo el esquema isabelino. En 2011 se publica Solo vos sos vos: Los sonetos de Shakespeare en traducción rioplatense, que incluye ya todos los sonetos en endecasílabos. Ambas ediciones son bilingües (en la versión rioplatense el original aparece como nota al pie) e incluyen prólogo del traductor.

I6 Ambas ediciones son del mismo año y en ninguno de los prólogos se hace referencia a la otra traducción, pero los 32 sonetos que incluye esta segunda edición están fechados entre 1970 y 1983, por lo que muchos de ellos serán, probablemente, previos a los sonetos «a su hija Susana». 
Fernando Marrufo (1990, México) traduce 85 sonetos en forma de soneto isabelino. Posteriormente, en 2002, aparece la traducción completa en una edición bilingüe con prólogo del traductor.

Carlos Pujol (1990, España) traduce todos los sonetos en alejandrinos blancos. Edición bilingüe con prólogo del traductor.

Juan Manuel Seco del Cacho (1991, España) traduce en forma de soneto isabelino el soneto 30, incluido en la edición bilingüe Antología de poesía inglesa. Siglos XVI-XX.

Carlos Herrero Quirós (1991, España) traduce en endecasílabos con rima en los pares y el dístico final el soneto 66 , recogido también en la $A n$ tología de poesía inglesa. Siglos XVI-XX.

Isidro Pliego Sánchez (1991, España) traduce en forma de soneto isabelino el soneto 114 , el último de los poemas de Shakespeare recogido en la antología antes citada.

Gustavo Falaquera (1993, España), nombre literario de Jesús Munárriz, traduce todos los sonetos en alejandrinos blancos. Edición bilingüe con prólogo del traductor.

Víctor Botas (1994, España) traduce en endecasílabos blancos el soneto 76, incluido en su poemario Las rosas de Babilonia.

Jorge Capriata (1996, Perú) traduce en verso libre 71 sonetos: $1,2,4,5,6,11,15,18,19,20,23,27$, $28,29,30,33,34,35,39,40,41,42,44,45,46$, $47,52,53,55,57,60,62,65,66,68,71,73,76,77$, $81,84,86,87,91,92,93,94,97,106,107,108$, $109,116,119,120,121,122,123,124,126,127,128$, 129,130, 133, 134, 138, 144, 151, 152, 154.

En 1999 aparece la versión completa de los sonetos de la mano de Hueso Húmero ediciones. Se trata de una edición bilingüe con prólogo del traductor.
William Ospina (1996, Colombia) traduce en alejandrinos rimados según el patrón isabelino 20 sonetos, incluidos en una edición especial de la revista Número: 1, 2, 6, 8, 9, 17, 27, 29, 32, 35, 42, $51,60,66,89,95,97,107,123$ y 133 . En 2003, la traducción de los 154 sonetos aparece publicada en Colombia por la editorial Norma y más tarde, en 2016, en España, por la editorial Navona. Todas estas ediciones son bilingües e incluyen prólogo del traductor.

Juan Arecha (1997, Argentina) traduce en verso libre los 40 primeros sonetos. Edición bilingüe con breve prólogo de los editores.

Alfredo Rodríguez López (1997, España) traduce, principalmente en endecasílabos blancos, 19 sonetos: 1, 2, 3, 4, 14, 19, 20, 27, 28, 29, 30, 42,50, $51,71,89,133,138,150$. Edición bilingüe con prólogo del traductor.

Alejandro Bekes (1997, Argentina) traduce 4 sonetos en endecasílabos formando tres cuartetos de rima abrazada y un pareado: $1,18,45,76$. Las traducciones aparecieron publicadas en el número 2 de la revista Fénix junto al original.

José María Álvarez (1999, España) traduce en verso libre todos los sonetos. Edición bilingüe con prólogo del traductor.

José Ramón Blanco y Gloria Freijo (1999, España) traducen en verso libre 14 sonetos incluidos en una edición bilingüe con prólogo de los traductores: 1, 18, 20, 32, 50, 55, 64, 75, 96, 104, 106, $110,122,130$.

Alejandro Carugati (1999, Argentina) traduce en verso libre 80 sonetos incluidos en una edición monolingüe con prólogo de los editores: 1 , $2,3,4,5,6,7,15,16,17,18,19,20,21,22,23,24,25$, $26,27,28,29,30,31,32,33,34,35,36,37,38,39$, $40,41,42,43,44,45,46,47,48,49,50,51,52,53$, $54,55,56,59,60,61,62,63,64,65,66,70,71,72$, 
574

$73,75,76,77,78,80,81,83,84,87,88,89,91,96$, 97. 106, 123, 130, 138, 146.

Juan Ramón Jiménez (1999, España) traduce en prosa los treinta primeros sonetos ${ }^{17}$.

Alfredo Gómez Gil (2000, España) traduce en verso libre todos los sonetos. Incluye dos versiones: una «traducción» y una «interpretación» (el prólogo lleva por subtítulo «LOS SONETOS DE SHAKESPEARE, libremente traducidos e interpretados por Alfredo Gómez Gil»). Se trata de una edición bilingüe con prólogo de Eberhard Schlotter.

Javier Adúriz y Agustín Adúriz Bravo (2000, Argentina) traducen en verso libre 30 sonetos: 15,18 , $19,23,24,29,43,44,45,55,57,63,64,66,71,73,74$, $76,77,83,85,86,94,101,116,123,129,130,140,147$. Edición bilingüe con prólogo de los traductores.

Ángel Rupérez (2000, España) traduce en alejandrinos blancos 16 sonetos incluidos en la $A n-$ tología esencial de la poesía inglesa: 2, 15, 18, 19, 30, 33, 53, 55, 60, 64, 65, 73, 87, 94, 106, 107. Edición bilingüe con prólogo del traductor.

Tomás Gray (2002, Chile) traduce todos los sonetos en forma de soneto castellano. Edición bilingüe con prólogo de Gray y de Miguel Arteche.

Luis Rutiaga (2002, México) traduce todos los sonetos en endecasílabos blancos. Edición monolingüe con prólogo del traductor.

Gema Vives (2003, España) traduce en versos de distintos metros rimados según el esquema isabelino 35 sonetos: $8,9,11,17,18,20,21,23,25$, 27, 29, 41, 49, 50, 52, 53, 54, 55, 56, 59, 65, 66, 71, 73, 74, 76, 79, 85, 102, 105, 106, 110, 121, 122, 123.

\footnotetext{
${ }^{17}$ Estas traducciones fueron publicadas en un volumen editado por Pérez Romero (1999). Se consideran un borrador y no una traducción final. Se desconoce la fecha exacta de estas traducciones, aunque Pérez Romero proporciona algunas estimaciones de posibles fechas.
}

Edición bilingüe que incluye una nota al final con algunas aclaraciones respecto a la traducción.

Antonio Rivero Taravillo (2004, España) traduce todos los sonetos en endecasílabos blancos. Edición bilingüe con prólogo del traductor.

Demetrio Fábrega (2004, Panamá) traduce en forma de soneto isabelino 8 sonetos, incluidos en la antología bilingüe Sonetos de Camoens, $\mathrm{Pe}$ trarca, Ronsard y Shakespeare: 24, 55, 65, 73, 92, 106, 107 y 113.

Carlos Gardini (2004, Argentina) traduce en endecasílabos blancos 20 sonetos, publicados en la revista Ideas (Universidad del Salvador): 2, $7,15,18,19,20,23,30,59,60,68,78,86,107,116$, 127, 128, 129, 144, 147.

Ariel Laurencio Tacoronte (2005, Cuba) traduce 57 sonetos en forma de soneto isabelino con rima asonante: 1, 2, 3, 12, 14, 18, 19, 22, 24, 27, 28, $29,30,33,43,44,50,51,53,54,55,60,63,64,66$, $71,73,75,87,91,92,94,99,104,105,106,107,109$, $113,116,117,118,119,121,123,124,126,127,129,130$, 138, 141, 144, 145, 147, 148, 150. Edición bilingüe con prólogo del traductor.

Marcelo Pellegrini (2006, Chile) traduce 21 sonetos en distintos metros con rima asonante siguiendo el esquema isabelino: $1,2,5,12,15,17$, $18,19,59,73,76,105,116,117,118,122,123,126$, 129, 130, 154. Edición bilingüe con prólogo del traductor.

Martín Casillas de Alba (2006-2007, México) traduce en prosa todos los sonetos publicados en 5 volúmenes. En 2017, aparece una nueva versión de la mano de la editorial Bonilla Artigas Editores. Ambas ediciones son bilingües y contienen prólogo, comentario y notas del traductor.

Eduardo Gallardo Ruiz (2007, España) traduce en prosa los 154 sonetos. Edición bilingüe con prólogo del traductor. 
Pablo Ingberg (2007, Argentina) traduce en alejandrinos blancos 106 sonetos. El volumen incluye la traducción de Mujica Lainez de 48 sonetos y los que faltaban en la versión de Mujica, traducidos por Ingberg: 8, 9, 10, 11, 12, 13, 14, 28, 44, 45, $46,47,48,49,50,51,52,54,56,57,58,63,64,66$, $67,68,69,70,72,73,74,75,76,77,78,79,80,81$, $82,83,84,85,86,87,88,89,90,92,93,94,95,97$, 98, 99, 100, 101, 102, 103, 104, 105, 107, 108, 109, $110,111,112,113,114,115,116,117,118,119,120,121$, $122,124,125,126,127,128,129,130,131,132,133$, $134,135,136,137,138,139,140,141,142,143,144$, $145,147,148,149,150,151,152,153,154$. Esta edición bilingüe incluye un prólogo de Ingberg.

Christian Law Palacín (2007, España) traduce en endecasílabos blancos 7 sonetos, publicados en la revista Clarín: 18, 34, 50, 78, 89, 106 y 129. Dos años más tarde, Bartleby publica su traducción de todos los sonetos en una edición bilingüe, con original como nota al pie, que incluye prólogo del traductor.

Pedro Pérez Prieto (2008, España) traduce todos los sonetos en forma de soneto isabelino. Edición bilingüe con prólogo del traductor.

Andrés Ehrenhaus (2009, España/Argentina) traduce todos los sonetos en forma de soneto isabelino con rima asonante, publicados por Galaxia Gutenberg (Barcelona) y Paradiso Ediciones (Buenos Aires) el mismo año. En 2018 aparece una original versión de Ehrenhaus de los Sonetos en forma de haikus, Los 154 haikus de Shakespeare $^{18}$.

I8 Esta edición consta más bien de una traducción intralingüística — pues, como se explica en el prólogo, el punto de partida es la traducción previa de Ehrenhaus al español-y de una intersemiótica -Elenio Pico convierte cada uno de los haikus en una ilustración que acompaña al texto. Algunos de estos poemas breves ya habían aparecido en la publicación Periódico de Poesía, editada por la Universidad Nacional Autónoma de México, con el divertido título de «Chespiritos.
Ignacio Gamen (2009, España) traduce todos

los sonetos en alejandrinos con rima asonante siguiendo el esquema isabelino. Edición monolingüe con prólogo del traductor.

José Miguel Santamaría López (2010, España) traduce en verso libre 21 sonetos, incluidos en el volumen Lengua, traducción, recepción: en honor de Julio César Santoyo: 1, 2, 3, 4 5, 6, 7, 8, 17, 18, 50, 52, 53, 54, 55, 60, 66, 70, 71, 76, 83.

Ramón Gutiérrez Izquierdo (2011, España) traduce todos los sonetos en alejandrinos con rima asonante/consonante siguiendo el esquema isabelino. Edición bilingüe con prólogo del traductor.

Luciano García García (2013, España) traduce todos los sonetos principalmente en alejandrinos con rima consonante siguiendo el esquema isabelino. Edición bilingüe con prólogo del traductor.

Bernardo Santano Moreno (2013, España) traduce todos los sonetos en forma de soneto isabelino. También incluye una traducción literal como nota al pie. Edición bilingüe con prólogo del traductor.

Álvaro García (2014, España) traduce 9 sonetos en forma de soneto isabelino con rima asonante: $17,18,27,31,32,44,66,116,130$. Se trata de una edición bilingüe.

Salvador D. Insa Sales (2016, España) traduce 21 sonetos en distintos metros rimados siguiendo el esquema isabelino: $1,2,3,18,19,26,27,28$, 29, 30, 31, 32, 33, 50, 51, 56, 57, 70, 71, 106, 107. Edición bilingüe con prólogo del traductor.

Gabriel Jiménez Emán (2016, Colombia) traduce en verso libre los ocho primeros sonetos, publicados por la revista Arquitrave.

Los sonetos haikusados» (disponible en: http://www.archivopdp.unam.mx/index.php/1646-ineditos?start=25). 
576 Ricardo Silva-Santisteban (2016, Perú) traduce 3 sonetos en alejandrinos blancos, incluidos en el número 6 de la revista Lucerna: 18, 30, 54.

Edgardo Scott (2018, Argentina) traduce en prosa 44 sonetos $^{19}: 1,2,4,5,6,15,17,18,19,23,25$, $27,30,31,32,38,40,42,44,53,55,59,63,65,67$, 70, 71, 73, 89, 90, 93, 100, 106, 114, 115, 123, 124, 126, 131, 133, 138, 144, 151, 154. Edición monolingüe con prólogo del traductor.

Carlos Clementson (2018, España) traduce en alejandrinos blancos 3 sonetos recogidos en $\mathrm{La}$ belleza es verdad: antología de poetas ingleses, una edición bilingüe con prólogo del traductor: 18 , 30 y 55 .

Javier Franco Aixelá (2019, España) es el editor de una traducción resultado de un proyecto académico de colaboración en el que cada una de sus estudiantes traduce un soneto bajo su supervisión. La edición incluye los primeros diecisiete sonetos y contiene el texto original, una versión en prosa con un resumen temático, un breve análisis retórico y una traducción poética en alejandrinos. También está precedida por un prólogo escrito por Franco Aixelá.

\section{AGRADECIMIENTOS}

Quiero dar las gracias a los traductores, bibliotecarios, libreros y lectores que me ayudaron a conseguir todas las ediciones aquí citadas, especialmente las publicadas en Latinoamérica.

\footnotetext{
I9 No sabemos si como guiño a su compatriota Mujica Lainez, Scott también suma un soneto más a la cuenta en la nota que sigue a su prólogo, en la que afirma que «se reúnen en este volumen 45 sonetos» (p. 13).
}

\section{BIBLIOGRAFÍA}

\section{Fuentes primarias}

BAtTISTESSA, Ángel J. (1969): Oír con los ojos. Shakespeare en algunos de sus Textos. La Plata: Universidad $\mathrm{Na}$ cional de La Plata.

BENOT, Eduardo (1895): Versiones inglesas o arte de traducir el inglés. Madrid: Sucesores de Hernando.

BотAs, Víctor (1994): Las Rosas de Babilonia. Sevilla: Renacimiento.

CARo, Miguel Antonio (1891) Sonetos de aquíy allí. Traducciones y refundiciones. Curazao: Bethencourt.

GAos, Vicente, ed. (1986): Traducciones poéticas completas. Valencia: Institución Alfonso el Magnánimo: Institució Valenciana d'Estudis i Investigació.

GardinI, Carlos (2004): Veinte Sonetos de Shakespeare. Ideas 1(2): 45-75.

GómEZ, Anselmo (1927): Grandes poemas universales. Madrid: Renacimiento.

GoNZÁlez RódENAS, Soledad y Arroyo, Eduardo (2006) Música de otros: Traducciones y paráfrasis. Barcelona: Círculo de Lectores, Galaxia Gutenberg.

GuILLÉN, Jorge (1967): Homenaje. Milan: All'Insegna del Pesce d'Oro.

LóPEZ OrTEga, Ramón, y Álvarez Rodríguez, Román, eds. (1991): Antología de poesía inglesa: Siglos XVI$X X$. Salamanca: s.n.

Madariaga, Salvador de (1919): Manojo de poesías inglesas, puestas en verso castellano. Cardiff: William Lewis.

MARISTANY, Fernando (1918): Las cien mejores poesías (líricas) de la lengua inglesa. Valencia: Cervantes.

Maristany, Fernando (1920): Florilegio. Las mejores poesías líricas griegas, latinas, italianas, portuguesas, francesas, inglesasy alemanas. Barcelona: Cervantes.

Martí-Miquel, Jaime (1895): El ramo de pensamientos. Poesías de autores extranjeros puestas en rima castellana. Madrid: Imprenta de Enrique Teodoro y Alonso.

Martí-Miquel, Jaime (1897): Flores de luz. Poesías de autores extranjeros puestas en rima castellana. Valencia: Pascual Aguilar.

MartíneZ Sierra, Gregorio (1912): Mamá. Comedia en tres actos. Madrid: Renacimiento. 
NúÑEZ RoldÁN, Francisco (1986): El siglo de oro de la lírica inglesa. Madrid: Visor.

Ocampo, Silvina, ed. (1949): Poetas líricos en lengua inglesa. Buenos Aires: Jackson.

OcAmpo, Silvina, ed. (1999): Poetas líricos en lengua inglesa. Barcelona: Océano.

Palacio, Eduardo L. del (1936): Sonetos. Blanco y Negro, 42 (2324): 131.

Peregrín Otero, Carlos (1966): Letras I. Londres: Tamesis Books.

Pérez Bonalde, Juan Antonio (1880): Ritmos. Nueva York.

Pérez Romero, Carmen (1999): Juan Ramón Jiménez traductor de Shakespeare. Huelva: Fundación Juan Ramón Jiménez.

Pомво, Rafael (1917): Traducciones poéticas. Bogotá: Imprenta Nacional.

Rivas, José Pablo (1920): Antología de poetas extranjeros antiguos y contemporáneos. Madrid: Sucesores de Hernando.

Rupérez, Ángel (2000): Antología esencial de la poesía inglesa. Madrid: Espasa Calpe.

SÁnchez Pesquera, Miguel (1922): Antología de líricos ingleses $y$ angloamericanos. Madrid: Sucesores de Hernando.

SAnTAmaría López, José Miguel (2010): Tiempo de Shakespeare: Vuelta de Tuerca a la Traducción de sus Sonetos. En Rabadán, Rosa, Guzmán González, Trinidad y Fernández López, Marisa, eds. Lengua, traducción, recepción: en honor de Julio César Santoyo. León: Universidad de León, 13-38.

SHAKESPEARE, William (1892a): «Amor verdadero». Traducido del inglés por Miguel Antonio Caro. $L a$ España Moderna, 48: 26.

ShaKeSPEARE, William (1892b): «Día y noche». Traducido del inglés por Miguel Antonio Caro. La España Moderna, 44: 185.

ShaKesPeARE, William (1893a): «Retractación». Traducido del inglés por Miguel Antonio Caro. La España Moderna, 49: 140.

ShAKESPEARE, William (1893b): «Joyas del corazón». Traducido del inglés por Miguel Antonio Caro. $\mathrm{La}$ España Moderna, 58: 48.

ShAKESPEARE, William (1915a): «Un soneto de Shakespeare». Traducido del inglés por José de Armas. Blanco y Negro, 1258: 12.
ShaKeSPEARE, William (1915b): «Varios sonetos de William Shakespeare». Traducido del inglés por José de Armas. Cuba Contemporánea IX (1): 73-77.

SHAKESPEARE, William (1916a): «Lírica inglesa: Sonetos». Traducido del inglés por José Pablo Rivas. Estvdio XV (44): 261-267.

ShakesPeARE, William (1916b): «Tres sonetos de Shakespeare». Traducido del inglés por Julio Arceval. España, 69: 15.

ShaKeSPeARe, William (1917): «Los sonetos de Shakespeare». Traducido del inglés por José Pablo Rivas. Caras y Caretas, 954: 87-89.

SHAKeSPEARE, William (1920): Las mejores poesías (líricas) de los mejores poetas. Traducido del inglés por José Pablo Rivas, Fernando Maristany, Carmela Eulate, and Gabriel de Zéndegui. Barcelona: Cervantes.

ShaKeSPEARE, William (1922): «Versión castellana de tres sonetos de Shakespeare». Traducido del inglés por Luis María Díaz. Nosotros XVII, XLV (172): 75-76.

ShakeSPEARE, William (1927): «Sonetos de Shakespeare (La Primera Serie)». Traducido del inglés por Mariano de Vedia y Mitre. Verbum, 69: 189-206.

SHAKESPEARE, William (1929a): Obras completas. Traducido del inglés por Luis Astrana Marín. Madrid: M. Aguilar.

SHAKESPEARE, William (1929b): «Sonetos de Shakespeare». Segunda serie. Traducido del inglés por Mariano de Vedia y Mitre. Verbum, 73: 165-76.

SHAKESPEARE, William (1937): «Tercera y cuarta serie de los Sonetos de Shakespeare». Traducido del inglés por Mariano de Vedia y Mitre. Nosotros, 12: 248-56.

SHAKESPEARE, William (1940): Diez sonetos de Shakespeare. Traducido del inglés por Patricio Gannon. Buenos Aires: Francisco Colombo.

SHAKESPEARE, William (1944a): 21 sonetos de William Shakespeare. Traducido del inglés por Eduardo Dieste. Montevideo: Independencia.

ShaKeSPEARE, William (1944b): Sonetos. Traducido del inglés por Angelina Damians de Bulart. Barcelona: Montaner y Simón.

SHAKESPEARE, William (1945): Siete sonetos. Traducido del inglés por Ángel Johan. Las Palmas de Gran Canaria: J. M. Trujillo.

SHAKESPEARE, William (1946): «Los sonetos XLIV y XLV 
578 de Shakespeare». Traducido del inglés por Mariano de Vedia y Mitre. Amicitia, 29: 4-9.

ShaKespeare, William (1952): «Cuatro sonetos de Shakespeare». Traducido del inglés por Manuel Mujica Lainez. Sur, 209-210: 74-78.

SHAKeSPEARE, William (1954): Los Sonetos de Shakespea$r e$. Traducido del inglés por Mariano de Vedia y Mitre. Buenos Aires: Guillermo Kraft.

SHAKESPEARE, William (1957): «Sonetos de Shakespeare». Traducido del inglés por Manuel Mujica Lainez. La Biblioteca IX (1): 52-57.

ShaKespeare, William (1958): «Sonetos de Shakespeare». Traducido del inglés por Manuel Mujica Lainez. Boletín de La Academia Argentina de Letras, no.23: 608-15.

Shakespeare, William (1963): Cincuenta sonetos de Shakespeare. Traducido del inglés por Manuel Mujica Láinez. Buenos Aires: Ediciones Culturales Argentinas.

SHAKeSPEARE, William (1964): «Sonetos de Shakespeare». Traducido del inglés por Mario Reyes Suárez. Cauce, 39-40.

ShaKeSPEARE, William (1968): Los Sonetos de William Shakespeare. Traducido del inglés por José Basileo Acuña. San José: Costa Rica.

SHAKeSPEARE, William (1972): «Soneto 71. Soneto 97». Traducido del inglés por María Alfaro. ABC (Madrid), 24 November 1972.

ShaKespeare, William (1974a): «Dos sonetos de Shakespeare». Traducido del inglés por Jenaro Talens. La Ilustración Poética Española e Iberoamericana, 2-3: 31-32.

ShaKespeare, William (1974b): Sonetos de amor. Traducido del inglés por Agustín García Calvo. Barcelona: Anagrama.

Shakespeare, William (1975): Poesía completa. Traducido del inglés por Fátima Auad and Pablo Mañé. Barcelona: Ediciones 29.

ShaKespeare, William (1976a): Los Sonetos. Traducido del inglés por Mario Jofré Gutiérrez. San Luis: Talleres Gráficos Modelo.

ShaKeSPEARE, William (1976b): Sonetos. Traducido del inglés por José Méndez Herrera. Barcelona: Plaza \& Janés.
ShaKeSPEARE, William (1977): 30 sonetos. Traducido del inglés por José Francisco Elvira Hernández. Ávila: Sexifirmo.

ShaKespeare, William (1980): «Doce sonetos de William Shakespeare». En En torno a Shakespeare. Homenaje a T.J. B. Spencer, edited by Manuel Ángel Cornejero, Traducido del inglés por Jenaro Talens, 241-48. Valencia: Instituto Shakespeare, Universidad de Valencia.

Shakespeare, William (1982): Sonetos. Traducido del inglés por Enrique Sordo. Barcelona: Los Libros de Plon.

ShaKeSPEARE, William (1987a): Monumento de amor: Sonetos de Shakespeare. Traducido del inglés por Carmen Pérez Romero. Caceres: Universidad de Extremadura.

ShaKesPeARE, William (1987b): Selección de los Sonetos de Shakespeare. Traducido del inglés por Mariano Bros. Barcelona: Albatros.

ShaKeSPeAre, William (1987c): Sonetos completos. Traducido del inglés por Miguel Angel Montezanti. La Plata: Universidad Nacional de La Plata.

ShakesPeare, William (1990a): 85 Sonetos. Traducido del inglés por Fernando Marrufo. Mérida D. F.: Universidad Autónoma de Yucatán.

Shakespeare, William (1990b): Sonetos. Traducido del inglés por Carlos Pujol. Granada: Comares.

SHAKESPEARE, William (1996a): 20 Sonetos. Traducido del inglés por William Ospina. Número, special issue.

Shakespeare, William (1996b): 71 Sonetos. Traducido del inglés por Jorge Capriata. Lima: La Mosca Azul.

ShaKesPeARe, William (1997a): Los Sonetos. Traducido del inglés por Mario Jofré. Mendoza: Diógenes.

SHAKESPEARE, William (1997b): Sonetos. Traducido del inglés por Alejandro Bekes. Fénix, 2.

ShAKESPEARE, William (1997c): Sonetos de William Shakespeare. Traducido del inglés por Alfredo Rodríguez López. Málaga: Cuadernos de Traducción.

ShakesPeare, William (1997d): Sonetos. Selección. Traducido del inglés por Juan Arecha. Buenos Aires: Página/12.

ShaKesPeARe, William (1998): Sonetos. Traducido del inglés por Mario Reyes Suárez. Bogotá: El Áncora. 
Shakespeare, William (1999a): Canciones y Poemas de Amor. Traducido del inglés por José Ramón Blanco and Gloria Freijo. Bilbao: Muelle de Uribitarte.

ShaKeSPEARE, William (1999b): Los Sonetos y Un lamento amoroso. Traducido del inglés por Jorge Capriata. Lima: Hueso Húmero.

Shakespeare, William (1999c): Poemas y Sonetos. Traducido del inglés por José Basileo Acuña. Lima: Pontificia Universidad Católica del Perú.

ShaKesPeARe, William (1999d): Sonetos. Traducido del inglés por José María Álvarez. Valencia: Pre-Textos.

ShaKeSPEARE, William (1999e): Sonetos. Traducido del inglés por Alejandro Carugati. Buenos Aires: Planeta.

ShaKeSPEARE, William (2000a): Los sonetos de Shakespeare. Traducido del inglés por Alfredo Gómez Gil. Madrid: Edaf.

SHAKESPEARE, William (2000b): Treinta sonetos. Traducido del inglés por Javier Adúriz and Agustín Adúriz Bravo. Buenos Aires: Ediciones del Dock.

ShakesPeAre, William (2002a): Sonetos. Traducido del inglés por Fernando Marrufo. Mexico City: Universidad Nacional Autónoma de México, Universidad Autónoma de Yucatán, Instituto de Cultura de Yucatán, Fundación Fernando Marrufo.

ShaKespeare, William (2002b): Sonetos. Traducido del inglés por Luis Rutiaga. Mexico City: Grupo Editorial Tomo.

SHAKESPEARE, William (2002c): Sonetos de amor de William Shakespeare. Traducido del inglés por Tomás Gray. Santiago de Chile: Al Margen Editores.

SHAKESPEARE, William (2003a): Shakespeare para recalcitrantes. Traducido del inglés por Gema Vives. Sevilla: Jamais.

SHAKESPEARE, William (2003b): Sonetos. Traducido del inglés por William Ospina. Bogota: Norma.

ShaKespeare, William (2005): Sonetos. Traducido del inglés por Ariel Laurencio Tacoronte. La Habana: Editorial Arte y Literatura.

SHAKESPEARE, William (2006a): Constancia y claridad. 21 sonetos de William Shakespeare. Traducido del inglés por Marcelo Pellegrini. Santiago de Chile: RIL Editores.

SHAKESPEARE, William (2006b): Los Sonetos de Shakespeare I, II y III. Traducido del inglés por Martín Casillas de Alba. Mexico City: El Globo Rojo.

ShaKeSPeARe, William (2006c): Monumento de amor: Sonetos de Shakespeare. Traducido del inglés por
Carmen Pérez Romero. Caceres: Universidad de Extremadura.

Shakespeare, William (2007a): Poemas. Traducido del inglés por Eduardo Gallardo Ruiz. Madrid: Pigmalión.

ShakesPeAre, William (2007b. Siete sonetos. Traducido del inglés por Christian Law Palacín. Clarín. Revista de Nueva Literatura 12 (67): 38-41.

SHAKESPEARE, William (2007c): Sonetos. Traducido del inglés por Gustavo Falaquera. Madrid: Hiperión.

ShakeSPEARE, William (2007d): Sonetos. Traducido del inglés por Manuel Mujica Lainez and Pablo Ingberg. Buenos Aires: Losada.

ShaKespeare, William (2008): Sonetos. Traducido del inglés por Pedro Pérez Prieto. Tres Cantos: Nivola.

ShakeSPEARE, William (2009a): Sonetos. Traducido del inglés por Antonio Rivero Taravillo. Cordoba: Almuzara.

ShaKespeare, William (2009b): Sonetos. Traducido del inglés por Christian Law Palacín. Madrid: Bartleby.

ShakeSPEARE, William (2009c): Sonetos de amor. Traducido del inglés por Ignacio Gamen. Sevilla: Renacimiento.

ShaKespeare, William (2009d): Sonetos y Lamento de una amante. Traducido del inglés por Andrés Ehrenhaus. Buenos Aires: Paradiso Ediciones.

ShAKESPEARE, William (2009e): Sonetos y Lamento de una amante. Traducido del inglés por Andrés Ehrenhaus. Barcelona: Círculo de Lectores Galaxia Gutenberg.

SHAKESPEARE, William (2011): Solo vos sos vos: los Sonetos de Shakespeare en traducción rioplatense. Traducido del inglés por Miguel Ángel Montezanti. Mar del Plata: Eudem.

ShakeSPEARE, William (2013a): Sonetos. Traducido del inglés por Bernardo Santano Moreno. Barcelona: Acantilado.

ShakeSPEARE, William (2013b): Sonetos y Querellas de una amante. Traducido del inglés por Luciano García García. Valencia: JPM.

SHAKESPEARE, William (2014a): Nueve sonetos de Shakespeare. Traducido del inglés por Álvaro García. Malaga: El Toro Celeste.

ShaKeSPEARE, William (2014b): Sonetos. Traducido del inglés por Jenaro Talens and Richard Waswo. Madrid: Cátedra. 
580 Shakespeare, William (2016a): Ocho sonetos. Traducido del inglés por Gabriel Jiménez Emán. Arquitrave, 63: 6-13.

ShaKespeare, William (2016b): Sonetos. Traducido del inglés por William Ospina. Barcelona: Navona.

SHAKeSPEARE, William (2016c): Sonetos. Traducido del inglés por Ricardo Silva-Santisteban. Lucerna 3 (6): 45.

Shakespeare, William (2016d): Sonetos de Amor. Traducido del inglés por Salvador D. Insa. Madrid: Poesía Eres Tú.

ShaKeSPEARe, William (2016e): Sonetos de Shakespeare. Traducido del inglés por Ramón Gutiérrez Izquierdo. Madrid: Visor Libros.

ShaKespeare, William (2017): Sonetos. Traducido del inglés por Martín Casillas de Alba. Mexico City: Bonilla Artiga.

ShakesPeare, William (2018a): Los 154 haikus de Shakespeare. Traducido del inglés por Andrés Ehrenhaus. Barcelona: La Fuga.

SHAKESPEARE, William (2018b): Sonetos. Traducido del inglés por Edgardo Scott. Buenos Aires: Interzona.

ShaKeSPEARE, William (2019):Sonetos. Edited by Javier Franco Aixelá. Zaragoza: Los libros del Innombrable.

Siles Artés, José (1979): Poesía inglesa. Antología bilingüe. Barcelona.

SiLES ARTÉs, José (2006): Poesía angloamericana: Antología bilingüe (Siglos XIV al XX). L’Eliana: Ajuntament de L'Eliana.

TRAVERSI, Derek (1948): Visión de Shakespeare. Traducido del inglés por Concha Vázquez. Barcelona: José Janés.

Traversi, Derek (1951): Shakespeare. Traducido del inglés por Concha Vázquez. Barcelona: Labor.

Velasco y Rojas, Matías de (1877): Breve estudio sobre los Sonetos de Shakespeare. Alicante: Galería Rembrandt.

Velasco y Rojas, Matías de (1889): Sonetos. Madrid: Montoya.

Vives Heredia, Pedro (1985a): Los Sonetos de William Shakespeare. Buenos Aires: Arauco.

Vives Heredia, Pedro (1985b): Los Sonetos de William Shakespeare a Su Hija Susana. Buenos Aires: Arauco.

VV. AA. (1947): La poesía inglesa. De los primitivos a los neoclásicos. Traducido del inglés por Marià Manent. Barcelona: Lauro.
VV. AA. (1983): Poesía inglesa de los siglos XVI y XVII. Traducido del inglés por Marià Manent. Madrid: Orbis.

VV. AA. (2004): Sonetos de Camoens, Petrarca, Ronsard y Shakespeare. Traducido del inglés por Demetrio Fábrega. Panama: Sibauste.

VV.AA. (2018): La belleza es verdad: Antología de poetas ingleses (de W. Shakespeare a W.B. Yeats). Traducido del inglés por Carlos Clementson. Madrid: Eneida.

ZÉnDEGUI, Gabriel de (1920): Sones de la lira inglesa. London: Oxford University Press.

\section{Referencias}

ABC (1927): Noticias de libros y revistas. $A B C$, 4 noviembre 1927.

Almonacid y Cuenca, Miguel (1898): Boletín bibliográfico español. Vol. I. Madrid: Ministerio de Fomento.

ANóNIMo (1921): Variedades. Literatura hispano-americana. Suplemento ilustrado IX(91): 7-8.

Astrana Marín, Luis (1927): Las versiones en verso. El Imparcial, 23 octubre 1927.

BARCIA, Pedro Luis (1966): Bibliografía shakespeariana. Publicaciones Hechas En la Argentina. En Shakespeare en la Argentina. La Plata: Universidad Nacional de La Plata, Facultad de Humanidades y Ciencias de la Educación, 99-114.

BISTUÉ, Belén (2013): Traducciones de Shakespeare al español en España e Hispanoamérica. Panorama histórico. Boletín de Literatura Comparada, 38:103-18.

Blakmore Evans, Gwynne (2006): The Sonnets. Cambridge; New York: Cambridge University Press

Burrow, Colin (2002): The Complete Sonnets and Poems. Oxford: Oxford University Press.

Campillo Arnaiz, Laura (2005): Estudio de los elementos culturales en las obras de Shakespeare y sus traducciones al español por Macpherson, Astrana y Valverde. Murcia: Universidad de Murcia, Departamento de Filología Inglesa.

Chateaubriand, François-René de (1871): Ensayo sobre la literatura inglesa (traducido del francés por Madina-Veytia, Francisco). Madrid: Gaspar y Roig.

DíAZ FernándeZ, José Ramón (2005): Towards a Survey of Shakespeare in Latin America. En KLIMAN, Bernice W. y SAntos, Rick J. eds. Latin American 
Shakespeares. Madison: Fairleigh Dickinson University Press, 293-326.

Escudero, Tanya (2021): The Translation of Verse Form. A Revision of Holmes' Model. Sendebar, 32, 1-23. DOI: $10.30827 /$ sendebar.v32.16892

Julí́ MARTíneZ, Eduardo (1918): Shakespeare en Espa$\tilde{n} a$. Traducciones, imitaciones e influencia de las obras de Shakespeare en la literatura española. Madrid: Tip. de la 'Rev. de arch., bibl. y museos'.

LA Voz (1932): Los que van deportados a Villa Cisneros son ciento cincuenta y cinco. La Voz, 17 septiembre 1932.

LóPEZ HERnÁNDEZ, Marcela (1998): El soneto y sus variedades. Salamanca: Ediciones Colegio de España.

MonteZANTI, Miguel Ángel (2005): "Entre tanta polvareda perdimos a Don Beltrán”: O qué fue de la polisemia'. Trans 9: 85-98.

Muñoz Calvo, Micaela (1987): Los Sonetos de Shakespeare: Traductores y traducciones españolas. Miscelánea: A Journal of English and American Studies, 8: 87-100.

PAR, Alfonso (1930): Contribución a la bibliografía espanola de Shakespeare. Barcelona: Instituto del Teatro Nacional.

Pérez Bonalde, Juan Antonio (1947): Poesías y traducciones (recopilación). Caracas: Ediciones del Ministerio de Educación Nacional.

Pujante, Ángel Luis (1989): El Shakespeare de Mario Reyes: Su traducción de los Sonetos. En SANToYo, Julio César, ed. Actas Del XI Congreso AEDEAN. Translation across Cultures. León: Universidad de León, 135-40.

Pujante, Ángel Luis (2009a): Shakespeare, sonetos escogidos: las primeras versiones castellanas. Murcia: Nausícaä.

Pujante, Ángel Luis (2009b): Shakespeare's Sonnets in Spanish: Rescuing the Early Verse Translations. Revista de Historia de La Traducción, 3.

SÁnchez Pesquera, Miguel (1922) Antología de líricos ingleses y angloamericanos. Madrid: Sucesores de Hernando.

SANTAMARía LóPEZ, José Miguel (2007): Censura y género "western" en la época de Franco: Traducciones genuinas y pseudotraducciones. En MERINo ÁlVAREZ, Raquel, ed. Traducción y censura en España
(1939-1985): Estudios sobre corpus TRACE: Cine, Narrativa, Teatro. Bilbao: Universidad de León, Universidad del País Vasco, 105-52.

ShAKESPEARE, William (1885): Obras dramáticas de Guillermo Shakespeare (traducido del inglés por MACPHERSON, Guillermo). Madrid: Luis Navarro.

X., X. 1929. Movimiento literario. La Voz, 31 diciembre 1929. 